\title{
Design and Analysis of an Excavator Bucket
}

\author{
${ }^{1}$ K.P.Sibi George, M.K.Sandeep, A.Praveenkumar, V.Saran, \\ ${ }^{2}$ Prof.A.Sivasubramaniam \\ ${ }^{I}$ Final year student, Department of Mechanical Engineering Saveetha School of Engineering, Saveetha \\ University, Chennai, India \\ ${ }^{2}$ Associate Professor, Department of Mechanical Engineering Saveetha School of Engineering, Saveetha \\ University, Chennai, India
}

\begin{abstract}
An excavator is a run of the mill water driven substantial obligation human-worked machine utilized as a part of general adaptable development operations, for example, burrowing, ground leveling, conveying loads, dumping stresses and straight footing. Subsequent to doing such operation, there is probability of softening of stick up tooth connector gathering and bowing of tooth point. The target of this paper is to outline an excavator can by utilizing CREO-parametric 2.0 programming. Model is sent out through IGES document design for lattice in examination programming Limit conditions and the strengths are connected at the tip of teeth of excavator container. Static examination is done in ANSYS 13.0 investigation programming. In this paper the anxieties created at the tip of excavator basin teeth are computed. Rate blunder between stress Explanatory outcome and stress ANSYS result are ascertained.
\end{abstract}

Keywords: Creo-parametric software, Digging Forcesand F.E.approach.

\section{INTRODUCTION}

An excavator is a piece of heavy equipment that is commonly used in construction work, mining work and work that requires lifting that can be too heavy for humans. An excavator is a vehicle that is engineered and consists of things that can be used such as a backhoe and also has a cab that tends to be mounted to the back pivot near the undercarriage. It also has tracks and wheels that it is running on.

As the utilization of excavator in everyday life is expanding for some reasons however the pertinent site is not examined legitimately due direness of work by the proprietor or the contractual worker because of which inappropriate treatment of it prompts harm of the ground connecting with instrument i.e. basin teeth. The teeth of the excavator are fundamental reaching some portion of it which starts things out in contact with the dirt while doing exhuming at different locales. So for this situation now and then the tooth purpose of the basin gets harm because of some uncalled for taking care of by the administrator, which prompts the harm of tip of teeth. Here I compute the worries at the tip of the teeth by systematically and Limited investigation approach and after that analyze their outcomes.

\section{CALCULATIONOFDIGGINGFORCES}

Bucket penetration into a material is accomplished by the can twisting power $(\mathrm{Fb})$ and arm swarm compel (Fs). The rating of these burrowing strengths is set by SAE J1179 standard "Pressure driven Excavator and Escavator: Burrowing force." Bucket twisting power $(\mathrm{Fb})$ is the compel created at the tip of teeth by the can chamber and digression to the bend of range Arm swarm compel (Fs) is the constrain produced at the tip of teeth because of arm barrel is the burrowing power created by the arm chamber and digression to circular segment of range .

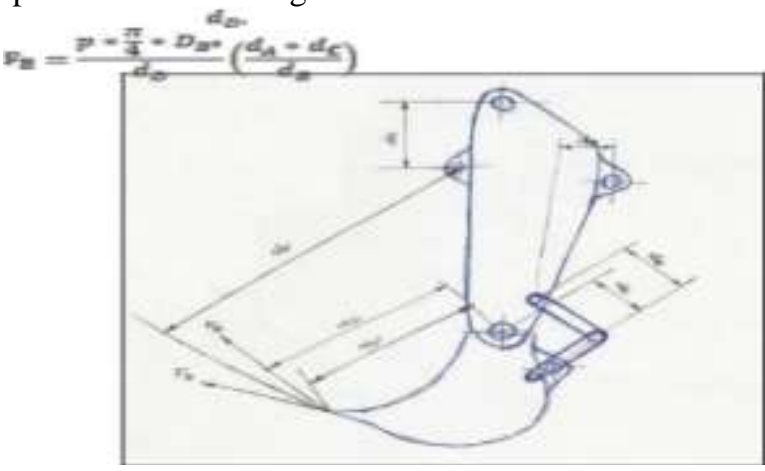

Fig1. Determination of Digging Forces 


$$
\mathrm{F}_{\mathrm{S}}=\frac{p * \frac{\pi}{4} * D_{A^{z}}}{d_{F}}\left(d_{E}\right)
$$

The figured breakout Constrain $(\mathrm{Fb})$ $=38690 \mathrm{~N}$ and computed Arm Swarm drive $(\mathrm{Fs})$ $=162478 \mathrm{~N}$. By utilizing CST strategy and Most extreme Shear Push Hypothesis the worry at the tip of the excavator Basin teeth $=96.39$ MPA.

\section{GEOMETRIC MODELLING OF ANEXCAVATOR BUCKET}

The geometry of the excavator pail has been gotten by an expulsion in CREO PARAMETRIC 2.0.first creates an excavator basin, teeth and bolt. At that point container, teeth and bolt are amassed together in get together device of CREO PARAMETRIC 2.0. This model is currently prepared to be transported in for preprocessing.

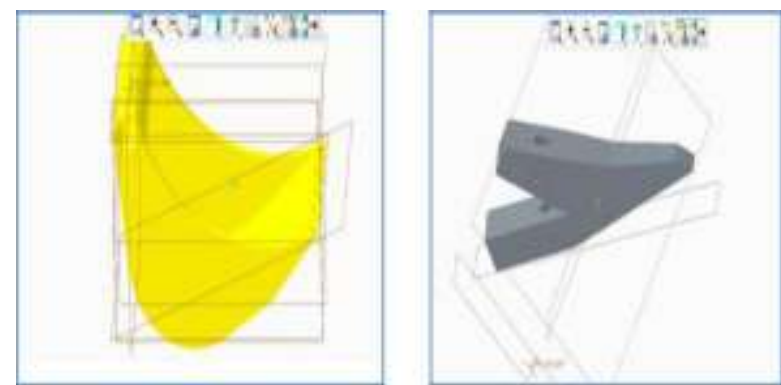

Fig.2. Create Excavator Bucket Fig.3.Create a Teeth

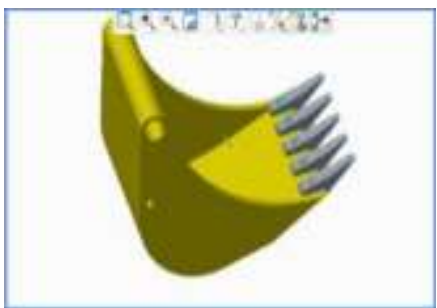

Fig.4 Create bucket Rivet

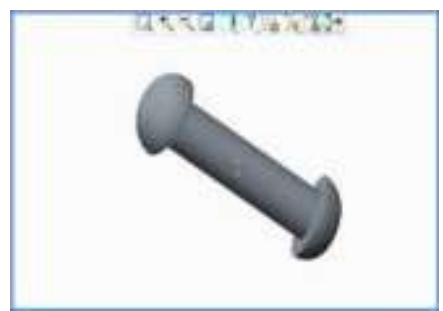

Fig.5 Assembly of Excavator Bucket

\section{FINITE ELEMENT ANALYSIS OF ANEXCAVATOR BUCKET}

The model was created in the CREO PARAMETRIC 2.0 programming. Limited component investigations are utilized as a part of outline change and enhancement purposes for some machine parts In this venture, my fundamental accentuation is on the pail tooth which starts things out in contact with soil for its contact misshapening and in addition the anxiety era for doing different sorts of operations at different destinations in India. To accomplish this, excavator can teeth have been dissected under most extreme stresses and diverse limit conditions. In ANSYS worry at every single components are resolved.Click on Main Menu $>$ Project $>$ Model $>$ Static Structural $>$ Solution. ANSYS displays the model with a color contours for stresses. Results of FEA as shown below: 


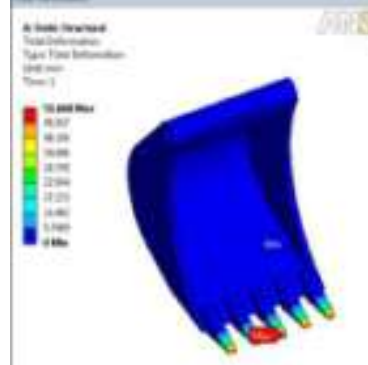

Fig.6. Total Deformation

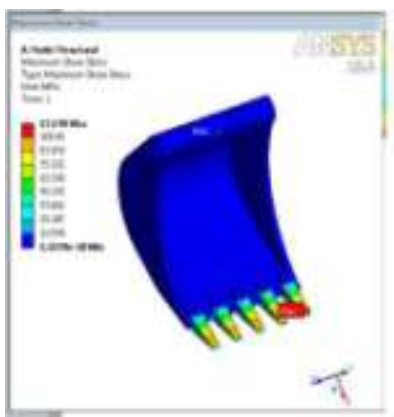

Fig.8. Maximum Shear Stress

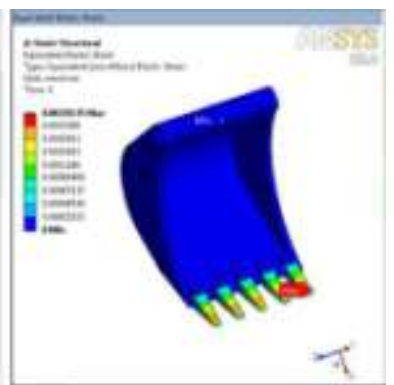

Fig.7.VoinMises Strain

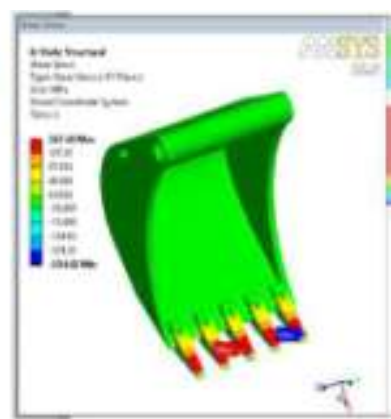

Fig. 9. Shear Stress

\section{RESULT AND DISCUSSION}

From the above analytical as well as ANSYS software analysis it has been found that the maximum stresses are generating at the tooth point due to the regular and maximum contact with the soil. These stresses can't be evaded yet can be appropriately controlled with legitimate use of can for the removal for different soil structures. Taking after fig's demonstrates the correlation between explanatory outcome and ANSYS result. Rate blunder between systematic outcome and ANSYS result are figured

Table 1: Comparison of Result

\begin{tabular}{|c|c|c|c|c|}
\hline Sr. & \multirow[t]{2}{*}{ Analysis } & Analytical & ANSYS & \%Error \\
\hline No. & & Result & Result & of Result \\
\hline \multirow[t]{2}{*}{1.} & Max Shear & \multirow[t]{2}{*}{$96.39 \mathrm{MPA}$} & 112.98 & \\
\hline & Stress & & MPA & $14.69 \%$ \\
\hline \multirow[t]{2}{*}{2.} & Shear & \multirow[t]{2}{*}{$157.67 \mathrm{MPA}$} & 167.42 & \\
\hline & Stress & & MPA & $5.82 \%$ \\
\hline
\end{tabular}

\section{VI. CONCLUSION}

In this paper, we outline an Excavator container by utilizing Creo parametric programming and investigation is finished by ANSYS 13.0 programming. The worry at the Tip of teeth of an Excavator pail is figured 96. 39 MPA and worry because of shearing of bolt is computed 157.67 MPA by logically. The worry at the tip of the teeth is computed 112.98 MPA and worry because of shearing of bolt 167.42 is ascertained. Rate mistake between scientific outcome and Ansys result are $14.69 \%$ and $5.82 \%$. According to the above examination, it is proposed that the can utilized for the unearthing reason ought to be legitimately checked for its application on the premise of the dirt strata. What's more, considering the disappointment of the tooth and bolt due the effect stacking, it is especially sparing to change the bolt as opposed to changing the entire tooth get together.

\section{REFERENCES}

[1] Zhou Hong-Bing, Wang Hui-Ke, GuoXinHua and Wang Shi-Huai, "Static Strength Analysis of Working Device of Hydraulic Excavator Based on MATLAB and ANSYS." Journal of Guangxi University (Natural Science Edition), Vol. 34 (06), pp.774-779, 2009.

[2] Lin Mingzhi and Xing Shuxin, "Finite Element Analysis to Boom of a Hydraulic 
Excavator." Construction Machinery and Equipment, Vol. 41, pp. 43-45, 2010.

[3] Huang Meimei, Zhao Tingting and ZouHuaqiang, "Finite Element Analysis of Boom of Hydraulic Excavator." Modern manufacturing technology and equipment, Issue 01, pp. 19- 20, 2011.

[4] LI Zhi-Jie, Wen-Quan Ming and Shi GuangLin, "Finite Element Analysis of Hydraulic Excavators based On Workbench." Journal of Guangxi University of Technology, Vol. 23 (03), pp. 32-35, 2012 GuiJu Zhang, Cai
Yuan-Xiao, Qing-Tan and You Yu-Mo, "Finite Element Analysis of Working Device for Hydraulic Excavator." Journal of Chemical and Pharmaceutical Research, Vol. 5 (12), pp. 123-128, 2013.

[5] Shengbin $\mathrm{Wu}$ and Xiaobao Liu, "Improvements for a Hydraulic Excavator's Boom."Applied Mechanics and Materials, Vol. 490-491, 510-513, 2014.

[6] Du Lin, "Fatigue Reliability of the Excavator's Boom." Machinery, Vol. 37 (05), $\quad$ pp. 25-27, 2010.

International Journal of Engineering Research and Applications (IJERA) is UGC approved Journal with Sl. No. 4525, Journal no. 47088.

K.P.Sibi George. " Design and Analysis of an Excavator Bucket" International Journal of Engineering Research and Applications (IJERA) 7.7 (2017): 20-23 